\title{
Timing of early laparoscopic cholecystectomy for acute calculous cholecystitis revised: Protocol of a systematic review and meta-analysis of results
}

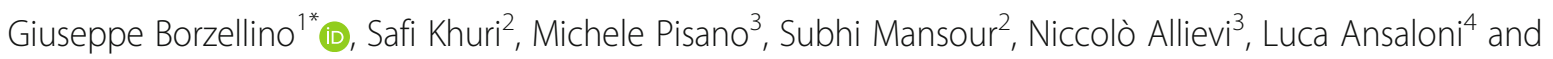
Yoram Kluger ${ }^{2}$

\begin{abstract}
Background: Early laparoscopic cholecystectomy has been adopted as the treatment of choice for acute cholecystitis due to a shorter hospital length of stay and no increased morbidity when compared to delayed cholecystectomy. However, randomised studies and meta-analysis report a wide array of timings of early cholecystectomy, most of them set at $72 \mathrm{~h}$ following admission. Setting early cholecystectomy at $72 \mathrm{~h}$ or even later may influence analysis due to a shift towards a more balanced comparison. At this time, the rate of resolving acute cholecystitis and the rate of ongoing acute process because of failed conservative treatment could be not so different when compared to those operated with a delayed timing of 6-12 weeks. As a result, randomised comparison with such timing for early cholecystectomy and meta-analysis including such studies may have missed a possible advantage of an early cholecystectomy performed within $24 \mathrm{~h}$ of the admission, when conservative treatment failure has less potential effects on morbidity. This review will explore pooled data focused on randomised studies with a set timing of early cholecystectomy as a maximum of $24 \mathrm{~h}$ following admission, with the aim of verifying the hypothesis that cholecystectomy within $24 \mathrm{~h}$ may report a lower post-operative complication rate compared to a delayed intervention.
\end{abstract}

Methods: A systematic review of the literature will identify randomised clinical studies that compared early and delayed cholecystectomy. Pooled data from studies that settled the early intervention within $24 \mathrm{~h}$ from admission will be explored and compared in a sub-group analysis with pooled data of studies that settled early intervention as more than $24 \mathrm{~h}$.

Discussion: This paper will not provide evidence strong enough to change the clinical practice, but in case the hypothesis is verified, it will invite to re-consider the timing of early cholecystectomy and might promote future clinical research focusing on an accurate definition of timing for early cholecystectomy for acute cholecystitis.

Keywords: Acute cholecystitis, Laparoscopic cholecystectomy, Timing, Morbidity

\footnotetext{
*Correspondence: gpborz@gmail.com

'Department of General Surgery, University Hospital of Verona Italy, Piazzale

A. STEFANI 1, 37128 Verona, Italy

Full list of author information is available at the end of the article
}

(c) The Author(s). 2020 Open Access This article is distributed under the terms of the Creative Commons Attribution 4.0 International License (http://creativecommons.org/licenses/by/4.0/), which permits unrestricted use, distribution, and reproduction in any medium, provided you give appropriate credit to the original author(s) and the source, provide a link to the Creative Commons license, and indicate if changes were made. The Creative Commons Public Domain Dedication waiver (http://creativecommons.org/publicdomain/zero/1.0/) applies to the data made available in this article, unless otherwise stated. 


\section{Background}

Laparoscopic cholecystectomy has been confirmed by the most recent guidelines to be the definitive treatment for acute calculous cholecystitis $[1,2]$, but the exact timing of the cholecystectomy remains still a matter of debate and aim of studies. Review and meta-analysis have reported clinical trials comparing early to delayed cholecystectomy in which, however, different definitions of early timing for cholecystectomy were adopted. More precisely, cholecystectomy was defined early when performed within 24, 48 or $72 \mathrm{~h}$ and even within $96 \mathrm{~h}$ following the admission or 1 week following the onset of symptoms [3-10]. Some results of published meta-analysis have been reported to be discordant, but mainly limited to the duration of the intervention [11]. All [2, 5-9] but one [4] found a shorter total hospital stay when cholecystectomy was performed early. Finally, all meta-analysis failed to find any differences in overall morbidity, bile duct injury, and conversion rate when comparing the two sets of timings [2-9].

Performing early cholecystectomy at $72 \mathrm{~h}$ or later may be questionable. The study of Arslan, by finding no outcome differences in randomising before and after $72 \mathrm{~h}$ during the same admission, invites to not consider $72 \mathrm{~h}$ as a break point of the timing of cholecystectomy [12]. Patients operated at $72 \mathrm{~h}$ may have had symptoms for 3 to 5 days at the time of cholecystectomy. On a pathological point of view, during this time, lymphoplasmacellular infiltration replaces polymorphonuclear cells, inducing a diagnostic shift from acute to chronic cholecystitis $[13,14]$. Moreover, in the study of Gutt et al, discharges were programmed as soon as possible following a 72-h period of medical treatment in the patients randomised in the delayed group [15], and in the trial of Johansson et al., mean duration of symptoms in the delayed group was reported to be $58 \mathrm{~h}$ [16]. This could be an advantage in setting the early timing at $72 \mathrm{~h}$ but it may have influenced analysis by a shift towards more balanced comparisons; patients submitted to early cholecystectomy at $72 \mathrm{~h}$ might not eventually be at a much higher risk of complications compared to those operated later during a second hospitalisation. On the other hand, medical treatment has a risk of failure with cumulative rates of 0 to $30 \%$ reported in the delayed groups [15-23] without any data provided for patients in the early groups. It can be therefore hypothesised that even in the early groups a rate of acute cholecystitis may be resolving and a rate may not be improving or worsening at the time of surgery, as it happened in the delayed group. As a result, the later early cholecystectomy is performed, the more patients within early and delayed cholecystectomy may have an overlaying risk of complications.

Until now and to the best of our knowledge no metaanalysis has reported results focused on immediate versus delayed cholecystectomy. By including different timing of early cholecystectomy, the conducted meta-analysis may have therefore missed the potential benefit, in terms of complications, of early cholecystectomy performed within $24 \mathrm{~h}$ following the admission.

\section{Objective}

The study will be performed to explore such a hypothesis by performing a systematic review of the literature and a meta-analysis of randomised clinical trials that compared early cholecystectomy performed within $24 \mathrm{~h}$ from the admission and delayed cholecystectomy in patients with an acute cholecystitis fit for an urgent surgical approach.

\section{Methods}

The meta-analysis will be performed according to the PRISMA statement for reporting reviews and metaanalysis [24]. The present protocol has been submitted for publication on the PROSPERO database for metaanalysis.

\section{Literature search to identify included studies}

A search of studies will be conducted on PubMed by two independent Authors. A term strategy based on PICOS acronym will be adopted, using subject headings and text words that allow to identify randomised studies including patients with acute cholecystitis, submitted to laparoscopic cholecystectomy, performed early after admission or delayed and reported overall complication rate. No limits of dates nor limits of language will be imposed. The following used search strategy will be used for PubMed:

Search: $(((()(($ cholecystitis[MeSH Terms] $))$ OR acute cholecystitis[MeSH Terms]) OR cholecystitis, acute[MeSH Terms])) AND ((((laparoscop*) OR celioscop*) OR coelioscop*) OR peritoneoscop*)) AND ((cholecystectomy) OR cholecystectomies $))$ AND ((((immediate) OR early) OR urgent) OR delayed) OR timing)) AND (((morbidit*) OR complication*) OR post-operative $))$ AND random*

Literature search will be completed by consulting the Cochrane Library, Embase and Clinical.trial.gov, and hand searching by reviewing all the references of the articles found to be of interest for this paper, including reviews and meta-analysis. Unpublished studies or data from presentations to congress were not considered.

\section{Study selection}

Two authors will independently assess studies. A first selection will be made based on the title and abstract. Papers will be selected for a full-text reading only if it is reported the study compares two different timing of laparoscopic cholecystectomy for patients with acute cholecystitis. Papers will not be selected if the title or abstract 
report clearly that the study is not comparative or that some categories of patients such as elderly will be excluded.

A second selection will be performed based on the full-text reading; papers will be included in the review only if it is specified the study is a comparative randomised trial, two different timing of laparoscopic cholecystectomy are compared, criteria for the diagnosis of acute cholecystitis are clearly defined, as well as population study and the different timing of surgery, and finally only if data on post-operative complications are reported, together with eventually bile duct injury and/or conversion rates and/or mortality.

Studies will be excluded in case they do not define early cholecystectomy by an exact numerical timing of the intervention but by imprecise indications such as immediate or as soon as possible, in case they do not define the population study, exclude some categories of patients and include patients with a different disease than acute cholecystitis.

\section{Data collection}

Data will be collected by two authors independently and reported in a pre-prepared sheet. Only ITT data will be collected. The primary outcome of the study will be the post-operative complication rates. This is the main component that may be directly influenced by the timing of cholecystectomy and that could change the course of the story of patients. Other parameters such as operative time, and intra-operative complications not requiring conversion could be used to assess the role of timing but they may be more subject to the influence of third factors and they may not finally change the course of the treatment. Furthermore, three other secondary outcomes will be registered; it is about bile duct injury, conversion and mortality, considered of interest since they all may change the course of the treatment:

In case of missing or not clear data on post-operative complications, authors will be contacted as an attempt to obtain or clarify the relevant data. Disagreements will be managed by discussing and asking a third author to decide for the final decision.

\section{Quality assessment of the selected studies}

Risk of bias will be independently assessed by two authors using the Cochrane collaborations tool for assessing risk of bias. Quality assessment will therefore focus on risk of bias arising from the randomisation process in the included studies, the allocation concealment, blinding, missing outcome data, measurement of the outcome and selective reporting.

Three different levels of risk, which are low, uncertain or high, will be incorporated according to the findings of the "risk of bias" assessment.
Publication bias will be explored by using a funnel plot in the presence of at least 10 trials $[25,26]$ and plan to use asymmetry of trial size against treatment effect to assess this bias.

\section{Statistical methods}

Since primary and secondary outcomes are dichotomous variables, relative risk and its $95 \%$ confidence interval will be calculated. Since studies will be selected based on defined criteria: all will be randomised clinical trials, including patients with well-defined acute cholecystitis, submitted to early or delayed cholecystectomy, no clinical nor methodological heterogeneity could be expected. We will therefore use a fixed-effect model [27] for the pooling RR and its $95 \%$ confidence interval.

Heterogeneity will be estimated with the $x^{2}$ test and the $I^{2}$ statistic. Heterogeneity will be excluded when $I^{2}$ will be less than $25 \%$ and considered moderate when less than $50 \%[28,29]$. The meta-analysis will be conducted using the ReviewManager (RevMan) computer programme Version 5.3 [30].

\section{Interpretation of findings}

The hypothesis that immediate laparoscopic cholecystectomy may reduce post-operative complications will be explored by pooling data of studies that settled the early intervention within $24 \mathrm{~h}$ after the admission and assessing whether immediate intervention reduce the rate of post-operative complication compared to delayed cholecystectomy.

On a methodological point of view, the only difference among selected studies is the different timing of early cholecystectomy. This allows to compare the results of the first group of studies that settled early cholecystectomy within $24 \mathrm{~h}$ from the admission to the results of a second group of included studies that settled early cholecystectomy later during the same admission. Such a comparison will complete the analysis of the results on post-operative morbidity providing furthermore a statistical evaluation of the results.

In case of heterogeneity, an analysis based on the number of included patients or based on the year of publication will also be performed. Studies including a limited number of patients are at risk of a II type error. By having calculated that 200 patients per arm would be required to consider a statistically significant $10 \%$ decrease from 20 to $10 \%$ of complications after respectively delayed and early cholecystectomy with alpha 0.05 and beta 0.8 , a sub-group analysis will be performed by analysing studies that have included less or more than 200 patients in at least one arm. The first randomised trial having been published more than 20 years ago and was related to an older experience, while more recent publications have less than a couple years, the role of gained 
experience will be assessed as a potential for heterogeneity by sub-group analysis comparing studies published more than 10 years ago and studies published less than 10 years ago.

A chi-square test for sub-group differences will be performed, setting a $p$ value at 0.05 to identify any significant differences.

\section{Sensitivity analysis}

A sensitivity analysis will be performed by comparing the fixed-effect model [27] and the random effect model using the DerSimonian Laird method [31]. The study is designed to explore immediate cholecystectomy within $24 \mathrm{~h}$ after the admission, but the theoretical key point of early cholecystectomy is potential waiting until $72 \mathrm{~h}$; we planned a sensitivity analysis by including all the studies setting early intervention at less than $72 \mathrm{~h}$ in the immediate early cholecystectomy group in comparison with a delayed group. We will complete the sensitivity analysis by evaluating the role of excluded studies because of incomplete information about the exact timing or methodological aspect of the studies including each of them in the immediate or delayed group according to the indicated or supposed timing of cholecystectomy.

\section{Considering the quality of evidence}

The quality of evidence will be evaluated according to the GRADE recommendations, the Cochrane Library [32]. Five domains that can lower the certainty of a body of evidence will therefore be considered as follows: risk of bias and inconsistency across studies; indirectness of studies that do not directly answer or apply to the review question; imprecision of studies reporting few people or events or wide confidence intervals allowing different conclusions and publication bias.

Rating up of the evidence will be considered in case of large effect.

\section{Discussion}

The study aims to evaluate the role of laparoscopic cholecystectomy performed within $24 \mathrm{~h}$ from the admission on post-operative complications rates in patients with acute cholecystitis. A 24-h mark for surgery has never been investigated by meta-analysis. The aim is based on the hypothesis that published meta-analysis, by including RCTs that compared early cholecystectomy up to $96 \mathrm{~h}$ from admission and even 1 week from symptoms with delayed cholecystectomy at 6-12 weeks may have missed the potential of urgent cholecystectomy performed within $24 \mathrm{~h}$ from the admission. To the best of our knowledge, no RCT comparing laparoscopic cholecystectomy within 24 and 72 or $96 \mathrm{~h}$ has been published until now. We proposed therefore a meta-analysis of results of RCTs comparing early and delayed cholecystectomy but including only those that considered early timing at no later than 24 $\mathrm{h}$ from admission. A sub-group analysis will be also performed in order to assess whether such a comparison will show a difference other meta-analysis have not shown until now. The present meta-analysis is not the more appropriate methodological approach to evaluate the efficacy of such a treatment strategy. However, in case it confirms our hypothesis that cholecystectomy within $24 \mathrm{~h}$ may reduce post-operative complication compared to delayed cholecystectomy while early cholecystectomy set at later timing did not, it could put forward a revision of the timing of early cholecystectomy for acute cholecystitis and provide the basis for future clinical research.

\section{Review status}

Searching relevant studies in the databases will begin in September. The review is expected to be complete by November 2019.

\section{Acknowledgements}

Not applicable.

\section{Authors' contributions}

GB conceived the systematic review and meta-analysis, developed the search and data collection strategy, designed and wrote the protocol, will participate in the assessment of the quality of the studies and risk of bias assessment, statistics, interpretation of findings, and assessment of the quality of evidence and will draft the manuscript. SK contributed to the development of the review protocol and will participate to the literature search and selection of the studies. MS will participate to the literature search and selection of the studies. MP contributed to the development of the review protocol and will participate to data collection and assessment of the quality of the studies and risk of bias assessment. NA will participate to the data collection, statistics, interpretation of findings and assessment of the quality of evidence. LA will provide critical revision of the manuscript. YK will take decisions in case of disagreement between two authors and will provide critical revision of the manuscript. All authors read, provided feedback and approved the final version of the protocol and all authors will read, provide feedback and approve the final version of the manuscript.

\section{Funding}

No sources of funding for the research.

Availability of data and materials

The datasets used and/or analysed during the current study will be available from the corresponding author on reasonable request.

Ethics approval and consent to participate

Not applicable. Ethical approval will not be required for this systematic review and meta-analysis as only a secondary analysis of data already available in scientific databases will be conducted.

\section{Consent for publication}

Not applicable. The manuscript will not contain data from any individual person.

\section{Competing interests}

The authors declare that they have no competing interests.

\section{Author details}

'Department of General Surgery, University Hospital of Verona Italy, Piazzale A. STEFANI 1, 37128 Verona, Italy. ${ }^{2}$ Department of General Surgery, Rambam Health Care Campus, Haifa, Israel. ${ }^{3} 1$ st Surgical Unit, Department of Emergency, Papa Giovanni Hospital XXIII, Bergamo, Italy. ${ }^{4}$ Department of Emergency and Trauma Surgery, Bufalini Hospital, Cesena, Italy. 
Received: 25 October 2019 Accepted: 20 December 2019

Published online: 03 January 2020

\section{References}

1. Okamoto K, Suzuki K, Takada T, Strasberg SM, Asbun HJ, Endo I, Iwashita Y, Hibi T, Pitt HA, Umezawa A, Asai K, Han HS, Hwang TL, Mori Y, Yoon YS, Huang WS, Belli G, Dervenis C, Yokoe M, Kiriyama S, Itoi T, Jagannath P, Garden OJ, Miura F, Nakamura M, Horiguchi A, Wakabayashi G, Cherqui D, de Santibañes E, Shikata S, Noguchi Y, Ukai T, Higuchi R, Wada K, Honda G, Supe AN, Yoshida M, Mayumi T, Gouma DJ, Deziel DJ, Liau KH, Chen MF, Shibao K, Liu KH, Su CH, ACW C, Yoon DS, Choi IS, Jonas E, Chen XP, Fan ST, Ker CG, Giménez ME, Kitano S, Inomata M, Hirata K, Inui K, Sumiyama Y, Yamamoto M. Tokyo Guidelines 2018: flowchart for the management of acute cholecystitis. J Hepatobiliary Pancreat Sci. 2018;25:55-72.

2. Ansaloni L, Pisano M, Coccolini F, Peitzmann AB, Fingerhut $A$, Catena F, Agresta F, Allegri A, Bailey I, Balogh ZJ, Bendinelli C, Biffl W, Bonavina L, Borzellino G, Brunetti F, Burlew CC, Camapanelli G, Campanile FC, Ceresoli M, Chiara O, Civil I, Coimbra R, De Moya M, Di Saverio S, Fraga GP, Gupta S, Kashuk J, Kelly MD, Koka V, Jeekel H, Latifi R, Leppaniemi A, Maier RV, Marzi I, Moore F, Piazzalunga D, Sakakushev B, Sartelli M, Scalea T, Stahel PF, Taviloglu K, Tugnoli G, Uraneus S, Velmahos GC, Wani I, Weber DG, Viale P, Sugrue M, Ivatury R, Kluger Y, Gurusamy KS, Moore EE. 2016 WSES guidelines on acute calculous cholecystitis. World J Emerg Surg. 2016;14;11:25.

3. Papi C, Catarci M, D'Ambrosio L, Gili L, Koch M, Grassi GB, Capurso L. Timing of cholecystectomy for acute calculous cholecystitis: a meta-analysis. Am J Gastroenterol. 2004;99:147-55.

4. Siddiqui T, MacDonald A, Chong PS, Jenkins JT. Early versus delayed laparoscopic cholecystectomy for acute cholecystitis: a meta-analysis of randomized clinical trials. Am J Surg. 2008;195:40-7.

5. Gurusamy KS, Davidson C, Gluud C, Davidson BR. Early versus delayed laparoscopic cholecystectomy for people with acute cholecystitis. Cochrane Database Syst Rev. 2013;30(6):CD005440.

6. Zhou MW, Gu XD, Xiang JB, Chen ZY. Comparison of clinical safety and outcomes of early versus delayed laparoscopic cholecystectomy for acute cholecystitis: a meta-analysis. Sci World J. 2014. https://doi.org/10.1155/ 2014/274516.

7. Wu XD, Tian X, Liu MM, Wu L, Zhao S, Zhao L. Meta-analysis comparing early versus delayed laparoscopic cholecystectomy for acute cholecystitis. $\mathrm{Br}$ J Surg. 2015;102:1302-13.

8. Cao AM, Eslick GD, Cox MR. Early Cholecystectomy is superior to delayed cholecystectomy for acute cholecystitis: a meta-analysis. J Gastrointest Surg. 2015;19:848-57.

9. Menahem B, Mulliri A, Fohlen A, Guittet L, Alves A, Lubrano J. Delayed laparoscopic cholecystectomy increases the total hospital stay compared to an early laparoscopic cholecystectomy after acute cholecystitis: an updated meta-analysis of randomized controlled trials. HPB (Oxford). 2015;17:857-62.

10. Lyu Y, Cheng Y, Wang B, Zhao S, Chen L. Early versus delayed laparoscopic cholecystectomy for acute cholecystitis: an up-to-date meta-analysis of randomized controlled trials. Surg Endosc. 2018;32:4728-41.

11. Song GM, Bian W, Zeng XT, Zhou JG, Luo YQ, Tian X. Laparoscopic cholecystectomy for acute cholecystitis: early or delayed?: Evidence from a systematic review of discordant meta-analyses. Medicine (Baltimore). 2016. https://doi.org/10.1097/MD.0000000000003835

12. Arslan Onuk ZA, Gündüz UR, Koç Ü, Kızılateş E, Gömceli I, Akbaş SH, Bülbüller N. Same-admission laparoscopic cholecystectomy in acute cholecystitis: the importance of 72 hours and oxidative stress markers. Ulus Travma Acil Cerrahi Derg. 2019;25:440-6.

13. Kumar V, Abbas AK, Fausto N. Chapter 2. In: Kumar V, Abbas AK, Fausto N, editors. Robbins and Cotran Pathologic Basis of Disease, 7th ed. Philadelphia: Elsevier Saunders; 2005. p 47.

14. Bochsler PN, Slauson DO. Inflammation and repair of tissue. In: Slauson DO, Cooper BJ, editors. Mechanisms of Disease: A Textbook of Comparative General Pathology, 3rd ed. St. Louis, MO: Mosby; 2002. p 141.

15. Gutt CN, Encke J, Koninger J, Harnoss JC, Weigand K, Kipfmuller K, Schunter O, Gotze T, Golling MT, Menges M, Klar E, Feilhauer K, Wolfram GZ, Ridwelski K, Ackmann S, Baron A, Schon MR, Seitz HK, Daniel D, StremmelW BMW. Acute cholecystitis: early versus delayed cholecystectomy, a multicenter randomized trial. Ann Surg. 2013;258(3):385-93.

16. Johansson M, Thune A, Blomqvist A, Nelvin L, Lundell L. Management of acute cholecystitis in the laparoscopic era: results of a prospective, randomized clinical trial. J Gastrointest Surg. 2003;7:642-5.
17. Lo C, Liu C, Fan S, Lai ECS, Wong J. Prospective randomized study of early versus delayed laparoscopic cholecystectomy for acute cholecystitis. Ann Surg. 1998;227:461-7.

18. Lai PBS, Kwong KH, Leung KL. Randomized trial of early versus delayed laparoscopic cholecystectomy for acute cholecystitis. BJS. 1998;85:764-7.

19. Davila D, Manzanares C, Picho ML, Albors P, Cardenas F, Fuster E, Trullenque R. Experience in the treatment (early vs. delayed) of acute cholecystitis via laparoscopy. Cir Esp. 1999;66(Suppl 1):233.

20. Kolla SB, Aggarwal S, Kumar A, Kumar R, Chumber S, Parshad R, Seenu V. Early versus delayed laparoscopic cholecystectomy for acute cholecystitis: a prospective randomized trial. Surg Endosc. 2004;18:1323-7.

21. Chandler CF, Lane JS, Ferguson P, Thompson JE, Ashley SW. Prospective evaluation of early versus delayed laparoscopic cholecystectomy for treatment of acute cholecystitis. Am Surgeon. 2000;66:896-900.

22. Macafee DA, Humes DJ, Bouliotis G, Beckingham IJ, Whynes DK, Lobo DN. Prospective randomized trial using cost-utility analysis of early versus delayed laparoscopic cholecystectomy for acute gallbladder disease. BJS. 2009;96:1031-40.

23. Saber A, Hokkam EN. Operative outcome and patient satisfaction in early and delayed laparoscopic cholecystectomy for acute cholecystitis. Minimally invasive surgery. 2014. https://doi.org/10.1155/2014/162643.

24. Liberati A, Altman DG, Tetzlaff J, Mulrow C, Gøtzsche PC, loannidis JP, Clarke M, Devereaux PJ, Kleijnen J, Moher D. The PRISMA statement for reporting systematic reviews and meta-analyses of studies that evaluate healthcare interventions: explanation and elaboration. BMJ. 2009;339:b2700.

25. Egger M, Davey SG, Schneider M, Minder C. Bias in metaanalysis detected by a simple, graphical test. BMJ (Clinical Research Ed.). 1997;315(7109):629-34.

26. Macaskill P, Walter SD, Irwig L. A comparison of methods to detect publication bias in meta analysis. Statistics in Medicine. 2001;20(4):641-54.

27. DeMets DL. Methods for combining randomized clinical trials: strengths and limitations. Statistics in Medicine. 1987;6:341-50.

28. Higgins JP, Thompson SG. Quantifying heterogeneity in a meta-analysis. Stat Med. 2002;21:1539-58.

29. Higgins JP, Thompson SG, Deeks JJ, Altman DG. Measuring inconsistency in meta-analyses. BMJ. 2003;327:557-60.

30. Review Manager (RevMan) [Computer program]. Version 5.3. Copenhagen: The Nordic Cochrane Centre, The Cochrane Collaboration, 2014.

31. DerSimonian R, Laird N. Meta-analysis in clinical trials. Control Clin Trials. 1986;7:177-88.

32. Schünemann $H$, Brożek J, Guyatt G, Oxman A (editors). The GRADE Working Group. GRADE Handbook for Grading Quality of Evidence and Strength of Recommendations. Available from gdt.guidelinedevelopment.org/app/ handbook/handbook.html Updated October 2013.

\section{Publisher's Note}

Springer Nature remains neutral with regard to jurisdictional claims in published maps and institutional affiliations.

Ready to submit your research? Choose BMC and benefit from

- fast, convenient online submission

- thorough peer review by experienced researchers in your field

- rapid publication on acceptance

- support for research data, including large and complex data types

- gold Open Access which fosters wider collaboration and increased citations

- maximum visibility for your research: over $100 \mathrm{M}$ website views per year

At $\mathrm{BMC}$, research is always in progress.

Learn more biomedcentral.com/submission 